\title{
CELLULOSE DIGESTION IN PRIMITIVE HEXAPODS: EFFECT OF INGESTED ANTIBIOTICS ON GUT MICROBIAL POPULATIONS AND GUT CELLULASE LEVELS IN THE FIREBRAT, Thermobia domestica (ZYGENTOMA, LEPISMATIDAE)
}

\author{
DAVID S. TREVES AND MICHAEL M. MARTIN*
}

\author{
Department of Biology \\ University of Michigan \\ Ann Arbor, Michigan 48109-1048
}

(Received January 12, 1994; accepted March 28, 1994)

\begin{abstract}
Antibiotic feeding studies were conducted on the firebrat, Thermobia domestica (Zygentoma, Lepismatidae) to determine if the insect's gut cellulases were of insect or microbial origin. Firebrats were fed diets containing either nystatin, metronidazole, streptomycin, tetracycline, or an antibiotic cocktail consisting of all four antibiotics, and then their gut microbial populations and gut cellulase levels were monitored and compared with the gut microbial populations and gut cellulase levels in firebrats feeding on antibiotic-free diets. Each antibiotic significantly reduced the firebrat's gut microflora. Nystatin reduced the firebrat's viable gut fungi by $89 \%$. Tetracycline and the antibiotic cocktail reduced the firebrat's viable gut bacteria by $81 \%$ and $67 \%$, respectively, and metronidazole, streptomycin, tetracycline, and the antibiotic cocktail reduced the firebrat's total gut flora by $35 \%, 32 \%$, $55 \%$, and $64 \%$, respectively. Although antibiotics significantly reduced the firebrat's viable and total gut flora, gut cellulase levels in firebrats fed antibiotics were not significantly different from those in firebrats on an antibioticfree diet. Furthermore, microbial populations in the firebrat's gut decreased significantly over time, even in firebrats feeding on the antibiotic-free diet, without corresponding decreases in gut cellulase levels. Based on this evidence, we conclude that the gut cellulases of firebrats are of insect origin. This conclusion implies that symbiont-independent cellulose digestion is a primitive trait in insects and that symbiont-mediated cellulose digestion is a derived condition.
\end{abstract}

Key Words-Cellulose digestion, cellulases, firebrats, Thermobia domestica, Lepismatidae, Zygentoma, Thysanura.

*'To whom correspondence should be addressed. 


\section{INTRODUCTION}

Of all living insect groups, the zygentomate families Lepidotrichidae and Lepismatidae (formerly in the order Thysanura) are probably nearest to the ancestral stock from which the higher insects evolved (Boudreaux, 1979; Kristenson, 1981). The family Lepismatidae includes firebrats and silverfish. The natural diets of firebrats and silverfish include lichens, terrestrial algae, fungal hyphae, fungal spores, yeasts, pollen, detritus, and small invertebrates (Lindsay, 1940; Smith, 1970; Wygodzinsky, 1972; Kaestner, 1973). In their feeding habits, therefore, they resemble other highly omnivorous scavengers and detritus-feeders, such as roaches. Cellulolytic capacity has been demonstrated in five species of Zygentoma: Ctenolepisma longicaudata (Lindsay, 1940), C. lineata (Lasker and Giese, 1956), Acrotelsa collaris (Modder, 1964, 1975), Lepisma saccharinum (Zinkler, 1983), and Thermobia domestica (Zinkler et al., 1986; Zinkler and Götze, 1987). Cellulolytic enzymes have been detected in both the crops and midguts of silverfish and firebrats. The crop is the most prominent section of the gut, often extending more than half of the animal's body length (Lindsay, 1940; Lasker and Giese, 1956; Bamhart, 1961; Zinkler et al., 1986; Zinkler and Götze, 1987). The hindgut is very small.

It has generally been asserted that the participation of gut microbes is not required for cellulose digestion in these primitive insects. The carefully designed study of cellulose digestion in the silverfish $C$. lineata by Lasker and Giese (1956) is regularly cited as a definitive demonstration of symbiont-independent cellulose digestion in the "Thysanura." In this study, the authors produced aposymbiotic (symbiont-free) animals and observed that the activity of the midgut fluid toward cellulose and the ability of the silverfish to degrade ${ }^{14} \mathrm{C}$-labeled cellulose were undiminished in the aposymbiotic animals. From this result they concluded that cellulose digestion must have been accomplished by enzymes produced by the insects. Unfortunately, this conclusion is somewhat weakened by two methodological ambiguities that would not have been evident in 1956 when this study was performed. For example, there is no indication that the purity of the labeled cellulose was checked before feeding it to the silverfish, and it is now known that preparations of labeled cellulose often contain significant amounts of labeled noncellulosic impurities. Indeed, it is not uncommon to find that as much as $10 \%$ of the counts in some commercial preparations can be extracted with water and an additional $15-20 \%$ can be extracted with base. Thus, the possibility cannot be ruled out that an impurity, not cellulose, was the source of the labeled carbon dioxide in the respired gasses collected from the aposymbiotic nymphs. Furthermore, in assaying cellulolytic activity in the gut fluid, Lasker and Giese used "regenerated cellulose" as the substrate. The preparation of "regenerated cellulose" (Trager, 1932) results in significant loss of crystallinity, making it much more easily degraded than native cellulose. 
Indeed, it is now known that the digestion of amorphous cellulose can be accomplished by endocellulases acting alone, whereas the efficient digestion of crystalline cellulose requires the synergistic action of a mixture of enzymes with different specificities (e.g., endocellulases, exocellulases, and cellobiases) (Coughlan and Ljungdahl, 1988). Consequently, finding undiminished activity toward "regenerated cellulose" in the guts of aposymbiotic animals does not establish that they are still able to digest native cellulose, but only that they secrete an endocellulase of unknown activity toward crystalline cellulose. Of course, these criticisms do not necessarily mean that Lasker and Giese are wrong in their conclusion that symbiont-independent cellulose digestion occurs in $C$. lineata, but only that evidence in favor of that conclusion is not compelling.

In this study we explore the origin of the soluble cellulases in the gut fluids of the common firebrat, Thermobia domestica (Zygentoma, Lepismatidae), by assessing the effects of ingested antibiotics on gut cellulase activity. The study is based upon the assumption that the level of gut cellulase activity should be reduced by the ingestion of antibiotics that effectively reduce the firebrat's gut microbial populations, if these populations are the source of the enzymes. We have used four antibiotics (nystatin, metronidazole, streptomycin, and tetracycline), each with activity against a different group of microbes, that have been shown to reduce the gut flora of other insects (Bracke et al., 1978; Jarosz, 1979; Taylor, 1982; Gilliam et al., 1988, Scrivener et al., 1989). We have determined the effects of the ingested antibiotics, singly and in combination, on consumption and survival, on the sizes of the microbial populations in the gut, and on the activity of the gut fluid toward microcrystalline cellulose.

In their study of $T$. domestica, Zinkler and Götze (1987) reported that "preliminary experiments with a diet containing a spectrum of antibiotics did not alter the cellulolytic enzyme activities significantly," but these authors included no description of, or data from, these "preliminary experiments," and we have been unable to find any subsequent publication describing this important study.

\section{METHODS AND MATERIALS}

Insect Collection and Maintenance. Firebrats were collected from buildings on the University of Michigan-Ann Arbor campus. Laboratory colonies were maintained at $35^{\circ} \mathrm{C}$ in 2.2-gallon Servin' Saver plastic containers in which were placed a beaker of water to maintain humidity and paper towels to provide places for the insects to hide. Firebrats were fed a diet of rolled oats (Lasker and Giese, 1956; Zinkler and Götze, 1987).

Antibiotics. Nystatin, tetracycline, streptomycin, and metronidazole were purchased from the Sigma Chemical Company (St. Louis, Missouri). Antibiotic 
concentrations used in the feeding studies were determined by the minimum inhibitory concentration (MIC) method (Davis et al., 1990). Antibiotics were incorporated into nutrient agar (Difco) (for antibacterial testing) or potato dextrose agar (Difco) (for antifungal testing) at various concentrations. Firebrat gut homogenate in $0.5-\mathrm{ml}$ aliquots of nutrient broth was spread onto the plates and incubated at $35^{\circ} \mathrm{C}$ for three days. The lowest concentration of antibiotic resulting in no growth of bacteria or fungi was the concentration chosen for the diets used in the feeding studies.

Diet Preparation for Antibiotic Feeding Studies. Lightly ground rolled oats were sterilized in an autoclave $\left(20 \mathrm{~min}, 121^{\circ} \mathrm{C}\right)$, cooled, and mixed with an aqueous solution of a single antibiotic or the antibiotic mixture. The rolled oat/ antibiotic slurry was then mixed thoroughly by hand and frozen at $-4^{\circ} \mathrm{C}$. Frozen diet was lyophilized $(8 \mathrm{hr})$ and then stored desiccated at $4^{\circ} \mathrm{C}$. Control diet (antibiotic-free) was prepared as above, substituting distilled water for the antibiotic solutions. Antibiotics were incorporated into the rolled oats at the following concentrations: nystatin, $200 \mathrm{units} / \mathrm{g}$; metronidazole, $500 \mu \mathrm{g} / \mathrm{g}$; streptomycin, $100 \mu \mathrm{g} / \mathrm{g}$; tetracycline, $200 \mu \mathrm{g} / \mathrm{g}$; antibiotic-cocktail (nystatin, $500 \mathrm{units} / \mathrm{g}$; metronidazole, $1000 \mu \mathrm{g} / \mathrm{g}$; streptomycin, $1000 \mu \mathrm{g} / \mathrm{g}$; tetracycline, $1000 \mu \mathrm{g} / \mathrm{g}$ ).

Antibiotic Feeding Experiments. Insects used for feeding experiments were starved three days prior to the start of each experiment and then offered the rolled oat diet with (experimental treatment) or without (control treatment) antibiotics. Fresh diet was offered every three days for the duration of each experiment. Paper towels normally present in the cages for hiding were replaced with plastic strips. Consumption (milligrams consumed per firebrat) was determined by subtracting the weight of the freeze-dried oat diet remaining after a threeday feeding period from the original dry weight of the diet offered. Firebrat survival was measured at three-day intervals. Viable gut bacteria, total gut microbes, and gut cellulase levels were measured at three-day intervals in the metronidazole, streptomycin, and tetracycline feeding studies, at weekly intervals in the nystatin feeding study, and after three and 12 days in the antibioticcocktail feeding study.

Preparation of Crude Cellulase Extracts. Firebrats were immobilized by cooling ( $1 \mathrm{~min},-4^{\circ} \mathrm{C}$ ) and dissected in $0.1 \mathrm{M}$ sodium acetate buffer (pH 5.0). Whole guts were removed by making a dorsal longitudinal incision in the insect body and teasing the gut away from the carcass and then homogenized individually by hand in $0.6 \mathrm{ml}$ of buffer for $1 \mathrm{~min}$ using a 15-ml glass homogenizer. The homogenate was centrifuged $\left(20 \mathrm{~min}, 4^{\circ} \mathrm{C}, 10,000 \mathrm{rpm} /\right.$ Sorvall SA-600 rotor) and the supernatant solution decanted. The pellet was resuspended in 0.6 $\mathrm{ml}$ of buffer that was used to rinse the homogenizer pestle and centrifuged as before. Supernatant solutions were pooled for column chromatography.

Column Chromatography and Extract Concentration. An aliquot $(1.0 \mathrm{ml})$ of the pooled supernatant solutions from a single firebrat gut extract was placed 
onto a Sephadex G-25M column $(1.2 \times 2.0 \mathrm{~cm}$, Pharmacia) and eluted with $0.1 \mathrm{M}$ sodium acetate buffer ( $\mathrm{pH} 5.0$ ). The first $3.5 \mathrm{ml}$ of eluant was collected, frozen using liquid nitrogen, and lyophilized $(8 \mathrm{hr})$. Cellulase assays were conducted on $0.05-\mathrm{ml}$ aliquots of a solution prepared by redissolving the freezedried material in $0.22 \mathrm{ml}$ of acetate buffer ( $\mathrm{pH} \mathrm{5.0)}$.

Cellulase Assay. Activity of the firebrat cellulase complex was determined by measuring the amount of reducing sugar released upon incubation of partially purified firebrat gut extract with microcrystalline cellulose (Dubois et al., 1956). An aliquot $(0.95 \mathrm{ml})$ of a microcrystalline cellulose suspension $(0.5 \%)$ in 0.1 $\mathrm{M}$ sodium acetate buffer ( $\mathrm{pH} 5.0$ ) was added to $0.05 \mathrm{ml}$ of partially purified gut extract. In controls, $0.05 \mathrm{ml}$ of thermally denatured $\left(110^{\circ} \mathrm{C}, 10 \mathrm{~min}\right)$ gut extract replaced the active gut extract. Following incubation $\left(2 \mathrm{hr}, 45^{\circ} \mathrm{C}\right)$, the cellulose/ gut extract suspensions were centrifuged $(3500 \mathrm{~g}, 2 \mathrm{~min})$, and an aliquot $(0.5$ $\mathrm{ml}$ ) of the supematant solution was assayed for reducing sugars by adding 0.5 $\mathrm{ml}$ of $5 \%$ phenol followed immediately by $2.5 \mathrm{ml}$ of concentrated sulfuric acid. This mixture was vortexed briefly and placed in a $25^{\circ} \mathrm{C}$ water bath $(20 \mathrm{~min})$, after which absorbance was measured at $490 \mathrm{~nm}$. Determinations were done in duplicate. Cellulase activity is expressed as micromoles of glucose equivalents liberated per gram whole gut (wet weight) per hour.

Viable Bacterial Counts and Viable Fungal Counts. Insects were weighed, immobilized at $-4^{\circ} \mathrm{C}$ and surface-sterilized by submersion in $70 \%$ ethanol (1 min), submersion in $15 \%$ bleach $(1 \mathrm{~min})$, then rinsed twice in sterile distilled water ( 1 min each). As a test of the effectiveness of this sterilization method, whole surface-sterilized firebrats were placed onto nutrient agar and potato dextrose agar and incubated for three days at $35^{\circ} \mathrm{C}$. Surface sterilized insects were dissected as described for cellulase assays, except that flame sterilized forceps were used for all transfer and dissections. Whole guts were placed in sterile tubes ( $20 \mathrm{~mm} \times 125 \mathrm{~mm}$ ) containing $0.5 \mathrm{ml}$ of nutrient broth (Difco) and 5 sterile sintered glass beads ( $6 \mathrm{~mm}$ diameter). Homogenation of the gut was achieved by vortexing at high speed for $1 \mathrm{~min}$, after which the gut homogenate was diluted with nutrient broth using 10-fold serial dilutions and then spread onto nutrient agar (viable gut bacteria) or potato dextrose agar (viable gut fungi). Determinations were conducted in duplicate. After a three-day incubation at $35^{\circ} \mathrm{C}$, counts of bacterial colony-forming-units (CFU) and viable fungal counts were made. Only bacterial plates containing 30-300 colonies were counted. Measurements of viable bacteria are expressed as colony-forming-units per whole gut, and viable gut fungi are expressed as fungal counts per whole gut.

Total Microbial Counts. Total counts of microorganisms in the firebrat's gut were made using the acridine orange-epifuorescence technique (Francisco et ai., 1973). Dilution tubes prepared for the estimation of viable bacterial and fungal counts were also used to estimate total gut microbes. A filter-sterilized solution of acridine orange $(1.0 \mathrm{ml}, 1 \%$ in $0.1 \mathrm{M}$ sodium bicarbonate buffer, 
$\mathrm{pH}$ 8.3) was mixed with an aliquot of gut homogenate that had been diluted with nutrient broth and made up to $10 \mathrm{ml}$ with filtered $0.1 \mathrm{M}$ sodium bicarbonate buffer, $\mathrm{pH}$ 8.3. Appropriate dilutions were made so that fields of view contained at least 30 cells. This solution was placed in a $10-\mathrm{ml}$ disposable syringe and filtered through a $0.22-\mu \mathrm{m}$ polycarbonate black membrane filter (Poretics, Livermore, California) using a 25-mm syringe filter (Gelman, Ann Arbor, Michigan). Following filtration, the membrane was quickly placed onto a glass slide, a drop of low-fluorescence immersion oil was added, and a cover slip was placed over the filter. Microbes were counted using an Olympus BH-2 microscope equipped with a Mercury 100 fluorescence unit, dichroic mirror B (DM-500 + O-515), excitor filter B (IF-490), and barrier filter O-530. Ten fields of view on the filter were counted using a $100 \times$ Splan oil objective. This method proved effective in distinguishing bacterial or fungal cells from nonmicrobial material. Microbial cells typically fluoresced red or green. Total gut microbial counts are expressed as microbes per whole gut.

Statistics. All statistics were done using Systat (Wilkinson, 1987). Firebrat consumption of antibiotic-containing and antibiotic-free diets was compared using a paired Student's $t$ test. Measurements of gut weights, gut cellulase levels, viable gut bacteria, viable gut fungi, and total gut bacteria were analyzed using a two-way analysis of variance (ANOVA) followed by contrasts with $\alpha$ adjusted for multiple comparisons by the Bonferoni method. To conform to assumptions underlying ANOVA, homogeneity of variances were tested using Bartlett's test $(\alpha=0.05)$ and normality was checked using rankit plots. Transformations were conducted on some data sets to pass Bartlett's test; viable gut bacteria were natural-log-transformed in the nystatin, streptomycin, and tetracycline feeding studies; total gut microbes were natural-log-transformed in the nystatin, metronidazole, and antibiotic-cocktail feeding studies; and viable gut fungi in the nystatin feeding study and gut cellulase levels in the tetracycline feeding study were square-root-transformed.

The streptomycin and tetracycline feeding experiments were carried out simultaneously and compared to one group of control firebrats in the laboratory but were compared to the control treatment independently during statistical analysis to negate interactions between the two antibiotic treatments.

\section{RESULTS}

\section{Diet Consumption.}

Antibiotic-containing and antibiotic-free diet consumption were monitored over the course of each feeding experiment to ensure that incorporation of antibiotics into the diet did not cause the firebrats to change their feeding behavior. Paired $t$ test analysis showed that none of the antibiotics singly (nystatin, $t=$ 
$0.21, d f=4, P>0.80$; metronidazole, $t=2.18, d f=4, P>0.05$; streptomycin, $t=0.80, d f=4, P>0.40$; tetracycline, $t=0.18, d f=4, P>$ $0.80)$ or in combination $(t=1.15, d f=3, P>0.30)$ significantly affected firebrat consumption. During the feeding experiments, consumption for the antibiotic-free and antibiotic-containing diets average $1.53 \pm 0.28$ and $1.61 \pm 0.28$ $\mathrm{mg} \mathrm{diet/insect/three-day} \mathrm{sampling} \mathrm{period,} \mathrm{respectively.}$

\section{Survival}

Firebrat survival was monitored over the course of each antibiotic feeding study to ensure that the concentrations of antibiotics used were not overly toxic. Except in the case of the antibiotic-cocktail feeding study, firebrats feeding on antibiotic-containing diets survived as well as firebrats feeding on the antibioticfree diet. Losses at each sampling period for the nystatin, metronidazole, streptomycin, and tetracycline feeding studies ranged from zero to three insects, with the maximum difference between firebrat deaths for the control and test treatments in any one sampling period being only two insects. Fifteen firebrats from the antibiotic-containing treatment died during the first sampling period of the antibiotic-cocktail feeding study compared to only three from the control treatment. However, after these initial losses, surviving firebrats feeding on the antibiotic-containing diet survived as well as insects feeding on the antibioticfree diet.

\section{Gut Weights}

Two-way ANOVA indicated that the gut weights for firebrats feeding on nystatin $(F=1.06, d f=1,24, P>0.30)$, metronidazole $(F=1.16, d f=$ $1,40, P>0.20)$, streptomycin $(F=1.21, d f=1,40, P>0.20)$, tetracycline $(F=0.77, d f=1,40, P>0.30)$ and the antibiotic-cocktail $(F=1.67, d f=$ $1,30, P>0.20$ ) were not significantly different from the gut weights of firebrats feeding on the antibiotic-free diet in each feeding experiment. Because there were no differences between gut weights in test and control animals, comparison of treatments involving viable gut bacteria and total gut microbes were made as counts per whole gut rather than per milligram of gut.

\section{Effects of Antibiotics on Populations of Gut Flora}

Nystatin. Firebrats feeding on the nystatin-containing diet had significantly fewer viable gut fungi compared to firebrats feeding on the nystatin-free diet $(F=12.41, d f=1,16, P \leq 0.01$ ) (Figure $1 \mathrm{~A}$ ). Overall, nystatin removed $89 \%$ of the firebrat's viable gut fungi. While nystatin significantly reduced the 

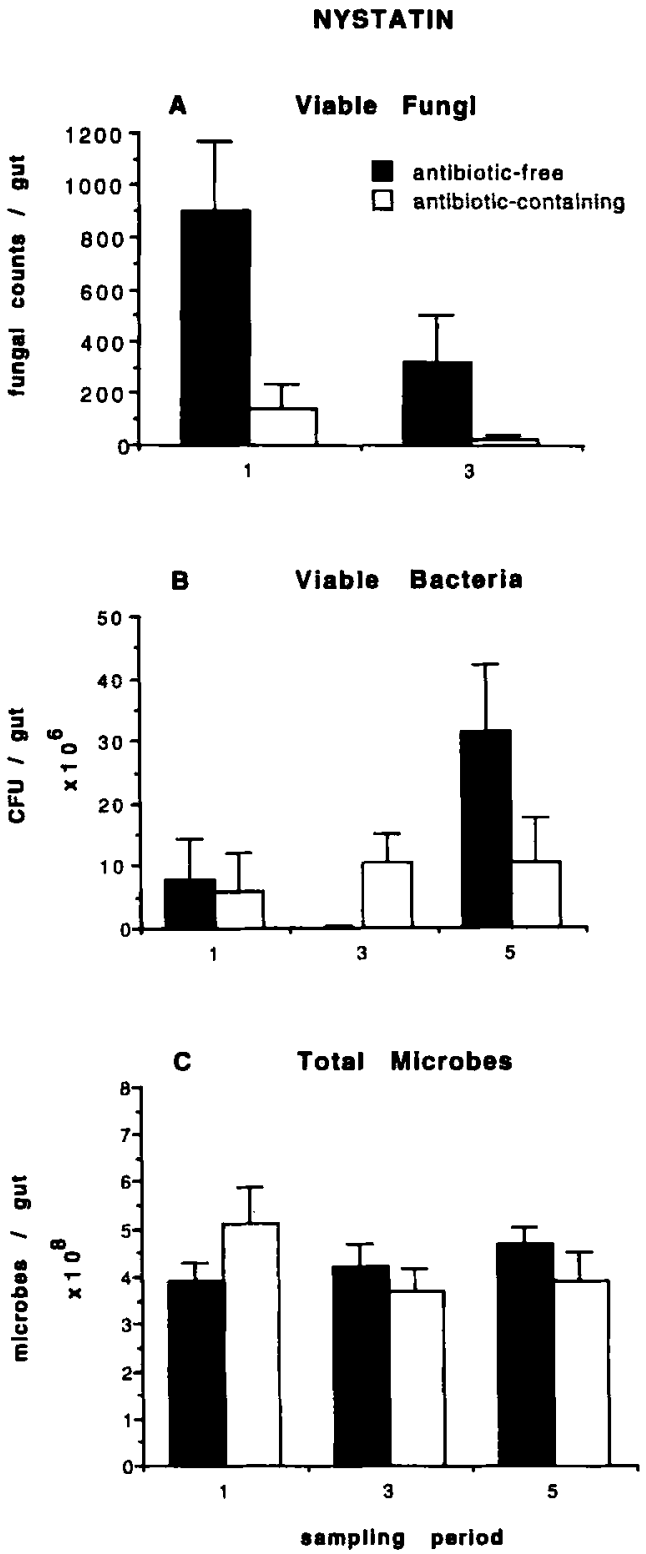

FIG. 1. Viable gut fungi (A), viable gut bacteria (B), and total gut microbes (C) measured during the nystatin feeding study. Sampling periods $1-3$ are 7, 14, and 21 days, respectively. Bars are mean with $S E M, N=5$. 
firebrat's viable gut fungi, viable gut bacteria $(F=0.037, d f=1,23, P>$ 0.80 ) (Figure 1B) and total gut microbes $(F=0.069, d f=1,24, P>0.70)$ (Figure 1C) were not significantly affected.

Ingested fungal spores and yeast cells are the most likely inocula responsible for the fungal colonies counted in these experiments, but we cannot rule out the possibility that some colonies were generated from multicellular fragments of hyphae or mycelia that remained viable in the gut. In any event, it is clear that the total population of potential fungal colony-forming units in the gut, in whatever form they may be present, is significantly reduced by nystatin. It is also evident that fungi make up a very small component of the gut flora compared to bacteria, which are four orders of magnitude more abundant.

Metronidazole. Firebrats feeding on the metronidazole-containing diet had significantly fewer total gut microbes that firebrats feeding on the metronidazolefree diet $(F=13.84, d f=1,40, P \leq 0.001)$ (Figure 2A). Counts of total gut microbes were reduced at each sampling period by metronidazole, and overall metronidazole reduced the firebrat's total gut flora by $35 \%$. The significant sampling period $\times$ treatment effect $(F=2.61, d f=4,40, P \leq 0.05)$ observed for counts of total microbes in this feeding study was due to the difference between treatments in sampling period 5 . Counts of total gut microbes in firebrats fed metronidazole were reduced by $82 \%$ compared to counts in firebrats fed the antibiotic-free diet in sampling period 5 , whereas the treatments differed by only $23 \%$ in the first four sampling periods.

Streptomycin. Counts of viable gut bacteria in firebrats feeding on the streptomycin-containing diet were not significantly different from counts in firebrats feeding on the antibiotic-free diet $(F=2.18, d f=1,36, P \geq 0.05)$ (Figure $2 \mathrm{~B}$ ). This nonsignificant difference is likely due to the high variability of the counts at each sampling period, and to sampling period 1 , when counts in the antibiotic-containing treatment were higher than counts in the antibioticfree treatment. After sampling period 1, viable counts in firebrats feeding on the antibiotic-containing diet were reduced compared to counts in firebrats feeding on the antibiotic-free diet.

Firebrats feeding on the streptomycin-containing diet had significantly fewer total gut microbes than firebrats feeding on the streptomycin-free diet $(F=$ 15.52, $d f=1,40, P \leq 0.001$ ) (Figure 2C). The firebrat's total gut microbes were reduced by streptomycin at each sampling period, and overall streptomycin removed $32 \%$ of the firebrat's total gut microbes. The significant sampling period $\times$ treatment effect $(F=2.92, d f=4,40, P \leq 0.05)$ for counts of total gut microbes in this feeding study is due to the difference between treatments in sampling period 1 . Counts of total microbes in firebrats fed streptomycin were reduced by $60 \%$ compared to counts in the control treatment in sampling period 1 , whereas the test and control treatments differed by an average of only $26 \%$ in the last four sampling periods. 
Viable Bacterla

antibiotic-tree

antibiotic-containing

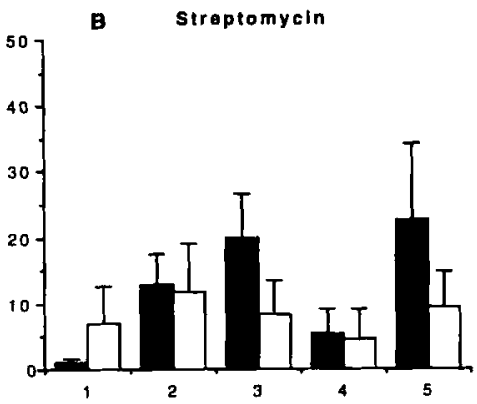

D Tetracycilne

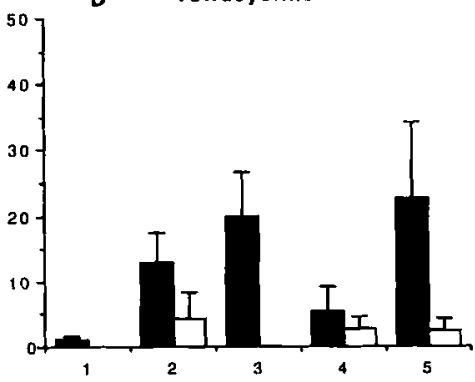

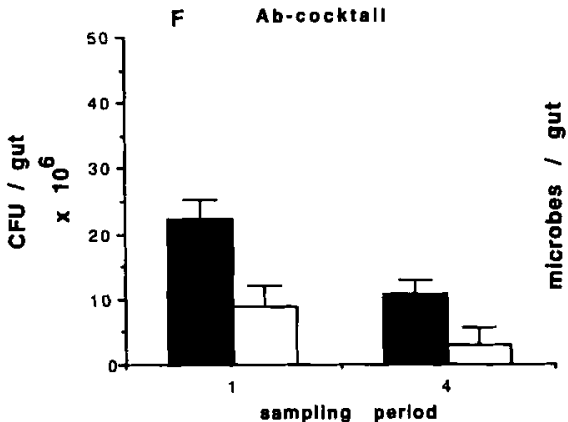
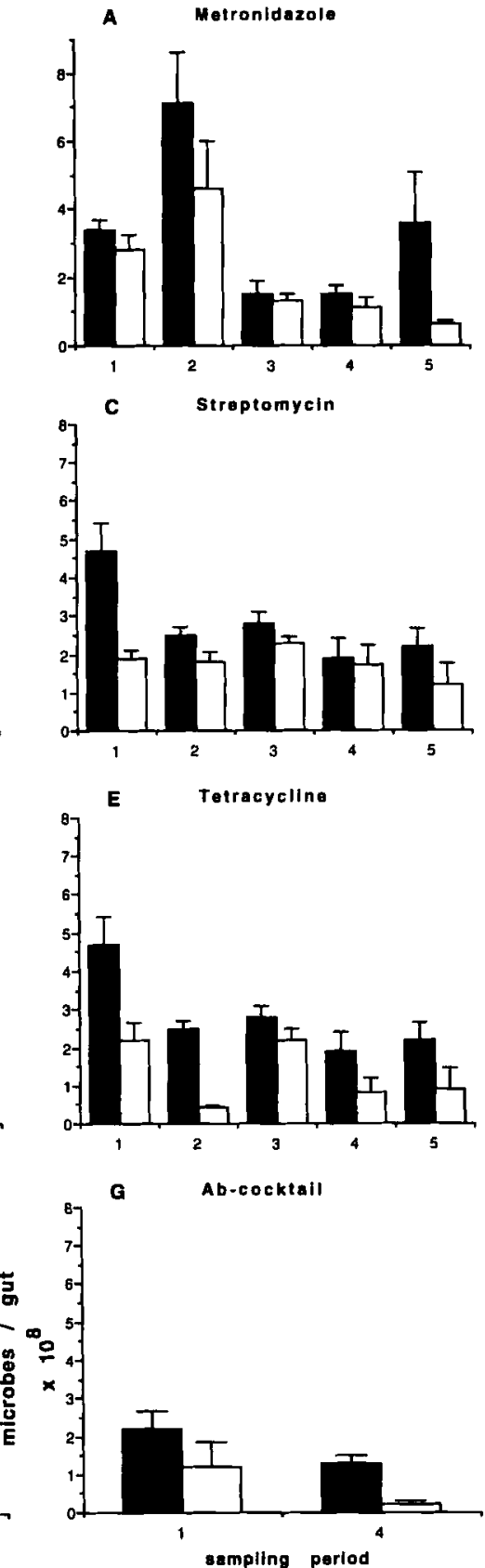
Tetracycline. Firebrats feeding on the tetracycline-containing diet had significantly fewer viable gut bacteria $(F=17.70, d f=1.32, P \leq 0.001)$ (Figure 2D), and significantly fewer total gut microbes $(F=30.85, d f=1.40, P \leq$ 0.001 ) (Figure 2E) than firebrats feeding on the tetracycline-free diet. Tetracycline reduced the firebrat's viable gut bacteria and total gut microbes at each sampling period, and overall tetracycline removed $81 \%$ of the firebrat's viable gut bacteria and $55 \%$ of the firebrat's total gut microbes.

Antibiotic Cocktail. Firebrats feeding on the antibiotic-cocktail diet had significantly fewer viable gut bacteria $(F=13.06, d f=1,29, P \leq 0.001)$ (Figure $2 F$ ) and significantly fewer total gut microbes $(F=19.43, d f=1,30$, $P \leq 0.001$ ) (Figure 2G). The antibiotic cocktail reduced the firebrat's viable gut bacteria and total gut microbes at each sampling period, and overall, the antibiotic-cocktail reduced the firebrat's viable gut by $67 \%$ and reduced total gut flora by $64 \%$.

\section{Changes in Populations of Gut Flora Over Time}

Nystatin. Viable gut fungi in both test and control treatments decreased significantly over time $(F=5.06, d f=1,16, P \leq 0.05$ ) (Figure 1A), but viable gut bacteria (Figure 1B) and total gut microbes (Figure 1C) in both treatments showed no significant decreases over time (summary statistics; Table 2 below). Viable gut fungi were $67 \%$ lower in sampling period 2 than in sampling period 1.

Metronidazole. The significant time effect observed in counts of total gut microbes ( $F=15,89, d f=4,40, P \leq 0.001$ ) (Figure 2A) was due to decreases in the counts measured during sampling periods 3,4 , and 5 . Counts of total gut

Fig. 2. Viable gut bacteria measured during the streptomycin (B), tetracycline (D) and Ab-cocktail (F) feeding studies and total gut microbes measured during the metronidazole (A), streptomycin (C), tetracycline (E), and Ab-cocktail (G) feeding studies. Sampling periods $1-5$ are $3,6,9,12$, and 15 days, respectively. Bars are mean with $\operatorname{SEM} ; N=$ 5 in the metronidazole, streptomycin, and tetracycline feeding studies except for viable gut bacteria in the streptomycin feeding study where $N=4$ for the test treatment at sampling period 1 and 2 , and viable gut bacteria in the tetracycline feeding study where $N=3$ for sampling periods 1,3 , and 4 (test treatment) and $N=4$ for sampling period 2 (control treatment). Sample sizes for viable gut bacteria in the Ab-cocktail feeding study at sampling period 1 (control treatment), sampling period 1 (test treatment), and sampling period 2 (both treatments) were $N=9,10$, and 7 , respectively. Sample sizes for total gut microbes in the Ab-cocktail feeding study at sampling period 1 (both treatments) and sampling period 2 (both treatments) were $N=10$ and 8 , respectively. 
microbes in sampling period 1 were significantly greater than those in sampling periods 3,4 , and 5 by $55 \%(F=12.21, d f=1,40, P \leq 0.001), 58 \%(F=$ 16.66, $d f=1,40, P \leq 0.001)$, and $32 \%(F=13.89, d f=1,40, P \leq 0.001)$ respectively, but not significantly different from sampling period 2 ( $F=5.26$, $d f=1.40, P=0.027$ ). Counts of total gut microbes measured in sampling period 2 were significantly greater than those measured in sampling periods 3 , 4 , and 5 by $76 \%(F=33.39, d f=1,40, P \leq 0.001), 78 \%(F=40.64, d f$ $=1,40, P \leq 0.001)$ and $64 \%(F=36.24, d f=1,40, P \leq 0.001)$. While counts of total microbes in the test treatment decreased consistently over the last three sampling periods, counts in the control treatment decreased only from sampling period 3 to sampling period 4 and then increased to initial levels at sampling period 5.

Streptomycin. Counts of viable gut bacteria in both test and control treatments fluctuated over the course of the streptomycin feeding study, and no significant time effect was detected (Figure 2B). The significant time effect observed for counts of total microbes in this feeding study $(F=4.66, d f=$ $4,40, P \leq 0.01$ ) (Figure $2 \mathrm{C}$ ) was due to a decrease in the control treatment after sampling period 1 . Counts of total gut microbes in sampling periods 2,3 , 4 , and 5 were reduced by an average of $38 \%$ compared to counts in sampling period 1. Two-way ANOVA, excluding sampling period 1, showed no significant sampling period effect $(F=1.73, d f=3,32, P=0.181)$, but still retained a significant treatment effect $(F=4.70, d f=1,32, P \leq 0.05)$.

Tetracycline. Counts of viable gut bacteria in both test and control treatments fluctuated over the course of this feeding study, and no significant decreases over time were detected (Figure 2D). The significant time effect observed for counts of total microbes in this feeding study $(F=8.88, d f=$ $4,40, P \leq 0.001$ ) (Figure $2 \mathrm{E}$ ) was due to decreases in counts after sampling period 1 . Sampling period 1 was significantly greater than sampling periods 2 , 4 , and 5 by $58 \%(F=21.99, d f=1,40, P \leq 0.001), 61 \%(F=23.80$, $d f$ $=1,40, P \leq 0.001)$, and $55 \%(F=20.51, d f=1,40, P \leq 0.001)$ respectively, but not significantly different from sampling period $3(F=5.46, d f=1,40, P$ $=0.025$ ).

Antibiotic Cocktail. Viable gut bacteria (Figure 2F) and total gut microbes (Figure $2 \mathrm{G}$ ) in both test and control treatments of this feeding study decreased over time, although this trend was only significant for viable counts $(F=8.98$, $d f=1,29, P \leq 0.01$ ). Viable counts decreased by $56 \%$ from sampling period 1 to sampling period 4 .

\section{Gut Cellulase Levels}

Although ingested antibiotics often significantly reduced the firebrat's viable gut bacteria and total gut flora, two-way ANOVA showed that the antibiotics ingested singly (nystatin, $F=0.45, d f=1,24, P>0.50$; metronidazole, $F$ 
$=0.024, d f=1,40, P>0.80 ;$ streptomycin, $F=0.80, d f=1,35, P>$ 0.30 ; tetracycline, $F=2.02, d f=1,38, P>0.10)$ or in combination $(F=$ $2.09, d f=1,32, P>0.10$ ) did not significantly reduce the firebrat gut cellulase levels (Table 1). Additionally, although the firebrat's gut microflora often decreased significantly over time, no corresponding decreases over time were observed in the firebrat's gut cellulase levels in either test or control samples in any of the feeding studies (nystatin: $F=0.28, d f=2,24, P>0.70$; metronidazole: $F=2.13, d f=4,40, P>0.05$; streptomycin: $F=0.88, d f=4,35$, $P>0.40$; tetracycline: $F=2.38, d f=4,38, P>0.05$; antibiotic cocktail: $F=1.73, d f=1,32, P>0.10$ ) (Table 1). No significant treatment $\times$ sampling period interactions were observed (Table 2).

\section{DISCUSSION}

In this study firebrats were fed diets containing four antibiotics (nystatin, metronidazole, streptomycin, and tetracycline), singly and combined in a cocktail containing all four. The presence of these antibiotics in the food had no effect on consumption or survival. Each of the antibiotics singly and the combination of all four caused significant reductions in the number of microorganisms present in the firebrat's gut but had no effect on levels of activity of gut fluid toward microcrystalline cellulose. These findings argue against a microbial origin for the soluble cellulases present in the gut fluids of firebrats.

In several of our experiments, microbial populations in the gut declined over time, even in firebrats fed an antibiotic-free diet. Apparently proliferation of microbes in the gut is not always rapid enough to maintain high steady-state populations, and the maintenance of microbial populations at the levels observed in wild-caught individuals requires a constant ingestion of bacteria to replace losses due to digestion and excretion. Decreases in the size of the populations of gut microbes associated with maintenance in a laboratory culture were never accompanied by a corresponding reduction in gut cellulase levels. This observation also argues against a microbial origin for the soluble cellulases present in the gut fluids of this species.

Our findings are, therefore, in agreement with earlier studies that suggest that silverfish (Lasker and Giese, 1956) and firebrats (Zinkler and Götze, 1987) digest cellulose without the aid of symbiotic gut microbes. However, two important caveats must be attached to this conclusion. First, in no case did the antibiotic treatment remove all of the firebrat's gut microflora. Even in the most effective treatment, the gut still contained a $10^{7}$ microbes. Even the removal of $90 \%$ of an insect's gut flora still leaves a large population of active microbes in the gut, and the possibility cannot be completely ruled out that cellulose 


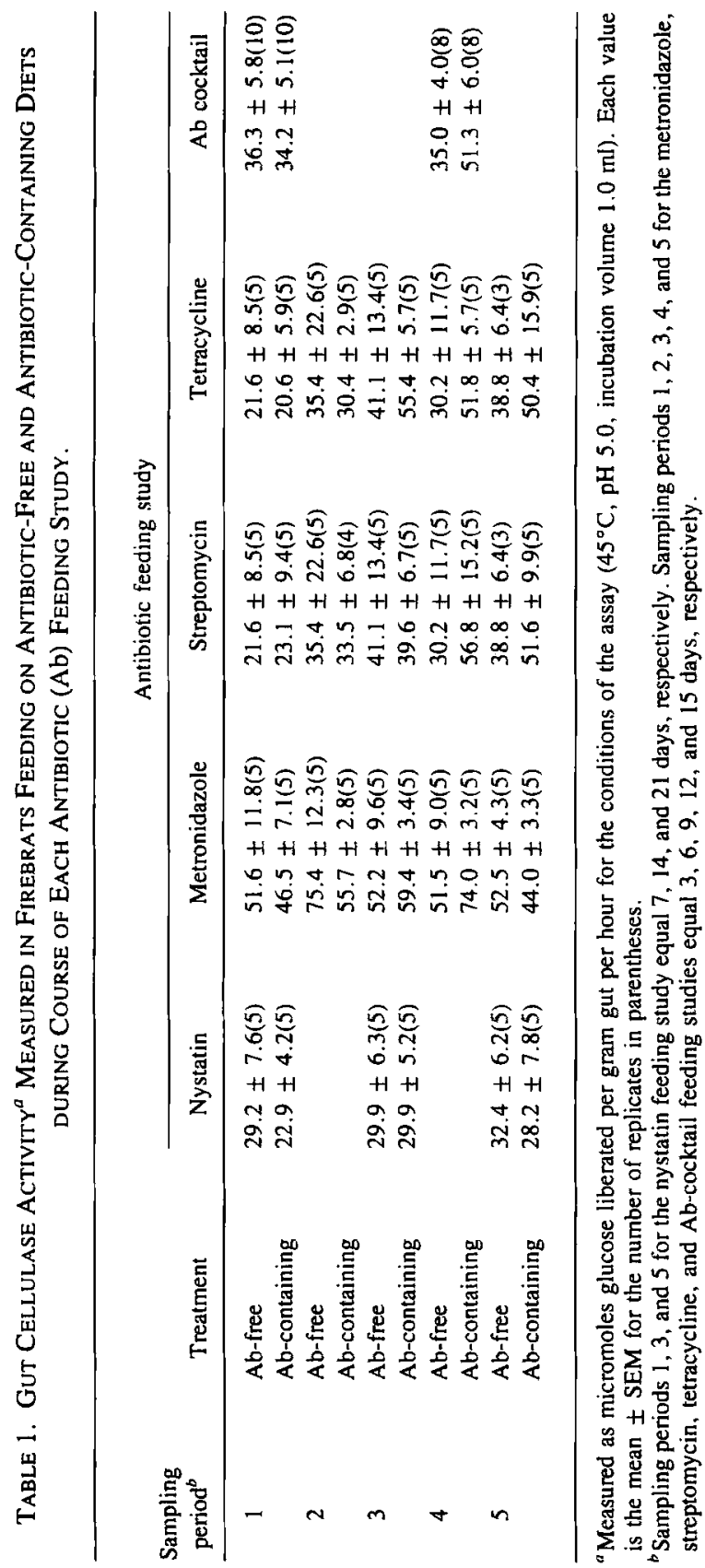


Table 2. F Statistics from Two-Way anovas on Viable Gut Bacteria, Total Gut Bacteria AND Gut Cellulase Levels ${ }^{a}$

\begin{tabular}{|c|c|c|c|c|c|}
\hline & \multicolumn{5}{|c|}{ Antibiotic feeding study } \\
\hline & Nystatin & Metronidazole & Streptomycin & Tetracycline & Ab-cocktail \\
\hline \multicolumn{6}{|l|}{ Viable gut bacteria } \\
\hline Treatment & $\begin{array}{c}0.037 \\
(1,23)\end{array}$ & & $\begin{array}{c}2.18 \\
(1,36)\end{array}$ & $\begin{array}{c}17.70^{* * *} \\
(1,32)\end{array}$ & $\begin{array}{c}13.06^{* * *} \\
(1,29)\end{array}$ \\
\hline Sampling period & $\begin{array}{c}1.84 \\
(2,23)\end{array}$ & & $\begin{array}{c}0.46 \\
(4,36)\end{array}$ & $\begin{array}{l}1.54 \\
(4,32)\end{array}$ & $\begin{array}{l}8.98^{* *} \\
(1,29)\end{array}$ \\
\hline Interaction & $\begin{array}{c}1.18 \\
(2,23)\end{array}$ & & $\begin{array}{c}0.40 \\
(4,36)\end{array}$ & $\begin{array}{l}0.69 \\
(4,32)\end{array}$ & $\begin{array}{l}0.96 \\
(1,29)\end{array}$ \\
\hline \multicolumn{6}{|l|}{ Total gut bacteria } \\
\hline Treatment & $\begin{array}{c}0.069 \\
(1,24)\end{array}$ & $\begin{array}{c}\left.13.84^{* * *}\right) \\
(1,40)\end{array}$ & $\begin{array}{c}15.52^{* * * *} \\
(1,40)\end{array}$ & $\begin{array}{c}30.85 * * * \\
(1,40)\end{array}$ & $\begin{array}{c}19.43^{* * *} \\
(1,30)\end{array}$ \\
\hline Sampling period & $\begin{array}{l}0.49 \\
(2,24)\end{array}$ & $\begin{array}{c}15.89 * * * \\
(4,40)\end{array}$ & $\begin{array}{l}4.66^{* *} \\
(4,40)\end{array}$ & $\begin{array}{l}8.88 * * * \\
(4,40)\end{array}$ & $\begin{array}{l}3.29 \\
(1,30)\end{array}$ \\
\hline Interaction & $\begin{array}{l}1.82 \\
(2,24)\end{array}$ & $\begin{array}{l}2.61^{*} \\
(4,40)\end{array}$ & $\begin{array}{l}2.92 * \\
(4,40)\end{array}$ & $\begin{array}{l}1.63 \\
(4,40)\end{array}$ & $\begin{array}{l}1.24 \\
(1,30)\end{array}$ \\
\hline \multicolumn{6}{|l|}{ Gut cellulase levels } \\
\hline Treatment & $\begin{array}{c}0.45 \\
(1,24)\end{array}$ & $\begin{array}{c}0.024 \\
(1,40)\end{array}$ & $\begin{array}{c}0.80 \\
(1,35)\end{array}$ & $\begin{array}{c}2.02 \\
(1,38)\end{array}$ & $\begin{array}{c}2.09 \\
(1,32)\end{array}$ \\
\hline Sampling period & $\begin{array}{c}0.28 \\
(2,24)\end{array}$ & $\begin{array}{l}2.13 \\
(4,40)\end{array}$ & $\begin{array}{c}0.88 \\
(4,35)\end{array}$ & $\begin{array}{c}2.38 \\
(4,38)\end{array}$ & $\begin{array}{c}1.73 \\
(1,32)\end{array}$ \\
\hline Interaction & $\begin{array}{c}0.13 \\
(2,24)\end{array}$ & $\begin{array}{l}2.26 \\
(4,40)\end{array}$ & $\begin{array}{c}0.47 \\
(4,35)\end{array}$ & $\begin{array}{c}0.41 \\
(4,38)\end{array}$ & $\begin{array}{c}2.85 \\
(1,32)\end{array}$ \\
\hline
\end{tabular}

"Degrees of freedom are in parentheses.

${ }^{b *} 0.05>P \geq 0.01,{ }^{* *} 0.01>P \geq 0.001,{ }^{* * *} P<0.001$.

digestion is mediated by microbial populations not affected by the antibiotics employed. Second, it is possible that the antibiotics did remove a significant portion of the firebrat's cellulolytic flora but also selected for resistant strains, and that following the initial reduction the resistance strains recovered to initial levels and continued to bring about cellulose digestion.

Our experiments were designed to address these two possible complications. First, we used four antibiotics with different activity profiles: nystatin, a naturally occurring fungicide active against yeasts and filamentous fungi (Greenwood, 1989); metronidazole, a nitroimidazole antibiotic active against anaerobic bacteria, trichomonads, and amoeba (Conte and Barriere, 1988); streptomycin, a broad spectrum aminoglycoside antibiotic active against aerobic gram-negative bacteria and some gram-positive species (Kurylowicz, 1976); and tetracycline, a broad spectrum antibiotic active against aerobic and anaerobic bacteria, mycoplasmas, chlamydiae, and rickettsiae (Conte and Barriere, 1988). If cellulose 
digestion were brought about by bacteria in firebrats, it seems unlikely that the subgroup of crop microflora responsible would be unaffected by any of the antimicrobial agents used. Second, we performed a series of closely spaced measurements of microbial numbers and cellulase activities in each feeding trial, an experimental design that would have detected an initial decline followed by a rebound of microbial numbers. No such pattern was observed in any of our experiments. Thus, we believe that this study provides strong support for the hypothesis that cellulose digestion in firebrats is not dependent upon the participation of symbiotic gut microbes.

Three mechanisms have been proposed to explain the ability of some insects to digest cellulose (reviewed in Martin, 1987, 1991): (1) cellulolysis mediated by microbial symbionts residing in or associated with the gut; (2) cellulolysis resulting from the presence of microbial cellulases originally present in the food that remain active in the gut following ingestion; and (3) symbiont-independent digestion brought about by enzymes exclusively of insect origin.

Evidence for symbiont-independent cellulose digestion mediated by enzymes exclusively of insect origin has been slow in coming but is mounting. The strongest cases for symbiont-independent cellulose digestion have been made for the nasute termites Nasutitermes walkeri and $N$. exitosus (Schulz et al., 1986; Hogan et al., 1988a) and the Australian wood-eating roach Panesthia cribrata (Scrivener et al., 1989). Slaytor (1992) has gone so far as to propose that cellulose digestion in all roaches and termites can be accomplished entirely by the action of endocellulases of insect origin. According to Slaytor (1992), symbiont-independent cellulose digestion in insects is possible, even in the absence of exocellulases, if endocellulases with low activity toward crystalline cellulose are produced in sufficient quantities, or if the food contains a significant component of noncrystalline cellulose that can be degraded by endocellulases alone. Endocellulases with low activity toward crystalline cellulose have been reported to be produced by eight species of termite (Potts and Hewitt, 1973, 1974a,b; Veivers et al., 1981, 1991; Schultz et al., 1986; Hogan et al., 1988a,b; Rouland et al., 1988a,b) and three species of roach (Scrivener et al., 1988; Zhang et al., 1993).

If cellulose digestion in the common firebrat and other primitive hexapods is mediated by insect-derived cellulases, then it is reasonable to conclude that symbiont-independent cellulolytic capacity is a primitive trait in insects. This conclusion is entirely compatible with Slaytor's suggestion (Slaytor, 1992) that cellulose digestion in termites and roaches can be accomplished effectively by endogenous enzymes, without the obligatory participation of microbial symbionts, and implies that symbiont-mediated cellulose digestion is a derived condition in insects. 


\section{REFERENCES}

BARNHARDT, C.S. 1961. The internal anatomy of the silverfish Ctenolepisma campbelli and Lepisma saccharinum (Thysanura; Lepismatidae). Ann. Entomol. Soc. Am. 54:177-196.

BoudreauX, H.B. 1979. Arthropod Phylogeny with Special Reference to Insects. Wiley \& Sons, New York.

Bracke, J.W., Cruden, D.L., and Markovetz, A.J. 1978. Effect of metronidazole on the intestinal microfiora of the American cockroach, Periplaneta americana L. Antimicrob. Agents Chemother. 13:115-120.

CONTE, J.E., and Barriere, S.L. 1988. Manual of Antibiotics and Infectious Diseases. Lea \& Febiger, Philadelphia, 392 pp.

COUGHLAN, M.P., and LJUNGDAHL, L.G. 1988. Comparative biochemistry of fungal and bacterial cellulolytic enzyme systems, pp. 11-30, In J.-P. Aubert, P. Beguin, and J. Millet (eds.). Biochemistry and Genetics of Cellulose Degradation. Academic Press, London.

Davis, B.D., Dulbecco, R., EISEN, H.N., and GinsberG, H.S. 1990. Microbiology. Lippincott, Philadelphia, $1215 \mathrm{pp}$.

Dubots, M., Gilles, K.A., Hamilton, J.K., Rebers, P.A., and Smith, F. 1956. Colorimetric methods for determination of sugars and related substances. Anal. Chem. 28:350-356.

FRANCISCO, D.E., MAH, R.A., and RABIN, A.C. 1973. Acridine orange-epifluorescence technique for counting bacteria in natural waters. Trans. Am. Microsc. Soc. 92:416-421.

Gilliam, M., LoRENZ, B.J., and RiChardson, G.V. 1988. Digestive enzymes and micro-organisms in honey bees, Apis mellifera: influence of streptomycin, age, season and pollen. Microbiol 55:95-114.

Greenwood, D. 1989. Antimicrobial Chemotherapy. Oxford Press, New York.

Hogan, M., Veivers, P.C., Slaytor, M., and Czolis, R.T. 1988a. The site of cellulose breakdown in higher termites (Nasutitermes walkeri and Nasutitermes exitosus). J. Insect Physiol. 34:891899.

Hogan, M., Schultz, M.W., Slaytor, M., Czolis, R.T., and O'Brien, R.W. 1988b. Components of termite and protozoal cellulases from the lower termite, Coptotermes lacteus Froggatt. Insect Biochem. 18:45-51.

JAROSZ, J. 1979. Yeastlike fungi from greater wax moth larvae (Galleria mellonella) fed antibiotics. J. Invert. Pathol. 34:257-262.

Kaestner, A. 1973. Lehrbuch der Speziellen Zoologie. Band I. Wirbellose. 3 Teil. Insecta. B. Speziellen Teil. Gustav Fisher Verlag, Stuttgart.

KrISTENSEN, N.P. 1981. Phylogeny of insect orders. Annu. Rev. Entomol. 26:135-157.

Kurylowicz, W. 1976. Antibiotics: A critical review. Polish Medical Publishers, 204 pp.

LASKER, R., and Giese, A.C. 1956. Cellulose digestion in the silverfish Ctenolepisma lineata. $J$. Exp. Biol. 33:542-553.

LINDSAY, E. 1940. The biology of the silverfish, Ctenolepisma longicaudata Esch. with particular reference to its feeding habits. Prac. R. Soc. Victoria (N.S.) 52:35-83.

MaRTJN, M.M. 1987. Invertebrate-Microbial Interactions: Ingested Fungal Enzymes in Arthropod Biology. Comstock Publishing Associates, Ithaca, New York.

Martin, M.M. 1991. The evolution of cellulose digestion in insects. Phil. Trans. R. Soc. London Ser. B. 333:281-288.

MODDER, W.W.D. 1964. The digestive enzymes in the alimentary system of Acrotelsa collaris (Thysanura: Lepismatidae). Ceylon J. Sci. (Bio. Sci.) 5:1-7.

ModDER, W.W.D. 1975. Feeding and growth of Acrotelsa collaris (Fabricius) (Thysanura, Lepismatidae) on different types of paper. J. Stored Prod. Res. 11:71-74.

PotTs, R.C., and HEwITT, P.G. 1973. The distribution of intestinal bacteria and cellulase activity 
in the harvester termite Trinervitermes trinervoides (Nasutitermitinae). Insectes Soc. 20:215220.

PotTs, R.C., and HewitT, P.H. 1974a. The partial purification and some properties of the cellulase from the termite Trinervitermes trinervoides (Nasutitermitinae). Comp. Biochem. Physiol. 47B:317-326.

PotTs, R.C, and HEwITT, P.H. 1974b. Some properties and reaction characteristics of the partially purified cellulase from the termite Trinervitermes trinervoides (Nasutitermitinae). Comp. Biochem. Physiol. 47B:327-337.

Rouland, C., Civas, A., Renoux, J., and PeTEK, F. 1988a. Purification and properties of cellulase from the termite Macrotermes mülleri (Termitidae, Macrotermitinae) and its symbiotic fungus Termitomyces sp. Comp. Biochem. Physiol. 918:449-458.

Rouland, C., Civas, A., Renoux, J., and Petek, F. 1988b. Synergistic activities of the enzymes involved in cellulose degradation, purified from Macrotermes mülleri and from its symbiotic fungus Termitomyces sp. Comp. Biochem. Physiol. 91B:459-465.

Schultz, M.W., Slaytor, M., Hogan, M., and O'Brien, R.W. 1986. Components of cellulase from the higher termite, Nasutitermes walkeri. Insect Biochem. 16:929-932.

SCrivener, A.M., SLAYTor, M., and Rose, H.A. 1989. Symbiont-independent digestion of cellulose and starch in Panesthia cribrata Saussure, an Australian wood-eating roach. J. Insect Physiol. 35:935-941.

SLAYTOR, M. 1992. Cellulose digestion in termites and cockroaches: What role do symbionts play? Comp. Biochem. Physiol. 103B:775-784.

Smith, E.L. 1970. Biology and structure of some California bristletails and silverfish. Pan-Pac. Entomol. 46:212-225.

TAYLOR, E.C. 1982. Role of aerobic microbial populations in cellulose digestion by desert millipedes. Appl. Environ. Microbiol. 44:281-291.

TRAGer, W. 1932. A cellulase from the symbiotic intestinal flagellates of termites and of the roach, Cryptocercus punctulatus. Biochem. J. 26:1763-1771.

Veivers, P.C., Musca, A.M., O'Brien, R.W., and Slaytor, M. 1981. Digestive enzymes of the salivary glands and gut of Mastotermes darwiniensis. Insect Biochem. 12:35-40.

Veivers, P.C., Mühlemann, R., Slaytor, M., Leuthold, R.H., and Bignell, D.E. 1991. Digestion, diet and polyethism in two fungus-growing termites: Macrotermes subhyalinus Rambur and M. michaelseni Sjostedt. J. Insect Physiol. 37:675-682.

WiLkinSON, L. 1987. Systat: The System for Statistics. Systat, Inc, Evanston, Illinois.

Wygodzinsky, P. 1972. A review of the silverfish (Lepismatidae, Thysanura) of the United States and the Caribbean Area. Am. Mus. Novit. 2482:1-26.

Zhang, J., Scrivener, A.M., Slaytor, M., and Rose, H.A. 1993. Diet and carbohydrase activities in three cockroaches, Calotampra elegans Roth and Princis, Geoscapheus dilatatus Saussure and Panesthia cribrata Saussure. Comp. Biochem. Physiol. 104A:155-161.

ZiNKLER, D. 1983. Ecophysiological adaptations of litter-dwelling Collembola and tipulid larvae, pp. 335-343, in New Trends in Soil Biology (P. Lebrun, ed.). Louvain-la-Nueve.

ZiNKLER, D., and GöTZE, M. 1987. Cellulose digestion by the firebrat Thermobia domestica. Comp. Biochem. Physiol. 88B:661-666.

ZINKLER, D., GöTZE, M., and FABIAN, K. 1986. Cellulose digestion in "primitive insects" (Apterygota) and oribatid mites. Zool. Beitr. N.F. 30:17-28. 